\title{
Cochrane
Library
}

Cochrane Database of Systematic Reviews

\section{Surgical interventions for entrapment and compression of the tibial and deep peroneal nerves including tarsal tunnel syndrome (Protocol)}

Perera N, Liolitsa D, Scott Hill C, Wordsworth D, Trivella M, Sinisi M, Manji H

Perera N, Liolitsa D, Scott Hill C, Wordsworth D, Trivella M, Sinisi M, Manji H.

Surgical interventions for entrapment and compression of the tibial and deep peroneal nerves including tarsal tunnel syndrome. Cochrane Database of Systematic Reviews 2017, Issue 6. Art. No.: CD010630.

DOI: 10.1002/14651858.CD010630.pub2.

www.cochranelibrary.com

Surgical interventions for entrapment and compression of the tibial and deep peroneal nerves including tarsal tunnel syndrome (Protocol)

Copyright $\odot 2017$ The Cochrane Collaboration. Published by John Wiley \& Sons, Ltd. 
TABLE OF CONTENTS

HEADER . . . . . . . . . . . . . . . . . . . . . . . . . . . . . . . . . . . . . . . 1

REASON FOR WITHDRAWAL . . . . . . . . . . . . . . . . . . . . . . . . . . . . . . . . . . . . . . .

WHAT'S NEW . . . . . . . . . . . . . . . . . . . . . . . . . . . . . . . . . . . . . . . . 1

SOURCES OF SUPPORT . . . . . . . . . . . . . . . . . . . . . . . . . . . . . . . . .

Surgical interventions for entrapment and compression of the tibial and deep peroneal nerves including tarsal tunnel syndrome

(Protocol)

Copyright $\odot 2017$ The Cochrane Collaboration. Published by John Wiley \& Sons, Ltd. 


\title{
Surgical interventions for entrapment and compression of the tibial and deep peroneal nerves including tarsal tunnel syndrome
}

\author{
Nirmal Perera ${ }^{1}$, Danae Liolitsa ${ }^{2}$, Ciaran Scott Hill $^{3}$, David Wordsworth ${ }^{4}$, Marialena Trivella ${ }^{5}$, Marco Sinisi ${ }^{6}$, Hadi Manji ${ }^{7}$ \\ ${ }^{1}$ UCL Institute of Child Health, Faculty of Population and Health Sciences, University College London, London, UK. ${ }^{2}$ St Mary's \\ Hospital, Imperial College Healthcare NHS Trust, London, UK. ${ }^{3}$ Neurosurgery, National Hospital of Neurology and Neurosurgery, \\ London, UK. ${ }^{4}$ Trauma and Orthopaedics, East Anglia Deanery, Luton, UK. ${ }^{5}$ Centre for Statistics in Medicine, University of Oxford, \\ Oxford, UK. ${ }^{6}$ Royal National Orthopaedic Hospital, Brockley Hill, Stanmore, UK. ${ }^{7}$ National Hospital for Neurology and Neurosurgery, \\ London, UK \\ Contact address: Nirmal Perera, UCL Institute of Child Health, Faculty of Population and Health Sciences, University College London, \\ 30 Guildford Street, London, WC1N 1EH, UK. perera.nirmal@gmail.com.
}

Editorial group: Cochrane Neuromuscular Group.

Publication status and date: Withdrawn from publication for reasons stated in the review, published in Issue 6, 2017.

Citation: Perera N, Liolitsa D, Scott Hill C, Wordsworth D, Trivella M, Sinisi M, Manji H. Surgical interventions for entrapment and compression of the tibial and deep peroneal nerves including tarsal tunnel syndrome. Cochrane Database of Systematic Reviews 2017, Issue 6. Art. No.: CD010630. DOI: 10.1002/14651858.CD010630.pub2.

Copyright (C) 2017 The Cochrane Collaboration. Published by John Wiley \& Sons, Ltd.

The editorial group responsible for this previously published document have withdrawn it from publication.

\section{REASON FOR WITHDRAWAL}

The authors have requested this protocol to be withdrawn as they are unable to complete this in the allocated time.

\section{WHAT'S NEW}

Date Event Description

12 June 2017 Amended Withdrawn. See Published notes

Surgical interventions for entrapment and compression of the tibial and deep peroneal nerves including tarsal tunnel syndrome 


\section{SOURCES OF SUPPORT}

\section{Internal sources}

- Ipswich Hospital library, NHS Trust, UK.

NHS Athens access

\section{External sources}

- No sources of support supplied 